\title{
Mentoring of Dental and Dental Hygiene Faculty: A Case Study
}

\author{
Robert A. Bagramian, D.D.S., M.P.H., Dr.P.H.; Russell S. Taichman, D.M.D., D.M.Sc.; \\ Laurie McCauley, D.D.S., M.S., Ph.D.; Thomas G. Green, Ph.D.; Marita Rohr Inglehart, \\ Dr. phil. habil.
}

Abstract: Given the predicted shortages of dental faculty in the United States, it is important to retain faculty members. Mentoring could play a crucial role in this context. The objectives of this case study were to explore how a six-year mentoring program in the Department of Periodontics and Oral Medicine at the University of Michigan School of Dentistry changed faculty members' perceptions of support from colleagues and their mentoring expectations. In addition, we sought to determine how junior versus senior faculty members and mentors versus mentees differed in their perceptions of faculty roles, their self-perceived competence, and their awareness of departmental expectations at the end of the program. Data were collected with self-administered surveys from twenty-five of the thirty-six faculty members in this department in 2002 (response rate: 69 percent) and from thirty-seven of the fifty-four faculty members in 2008 (response rate: 69 percent). The results showed that the perceptions of support from colleagues improved significantly over the six-year period. During the same time period, mentoring expectations increased. In 2008, junior faculty members as compared to senior faculty members remained less positive about their role as faculty members, felt less well prepared for their professional life, and were less aware of departmental expectations. In conclusion, a departmental mentoring program resulted in improved support from colleagues and increased expectations concerning mentoring experiences. However, future targeted interventions are needed to address the identified differences between junior and senior faculty members. Recommendations for faculty mentoring efforts are discussed.

Dr. Bagramian is Professor of Dentistry; Dr. Taichman is Professor of Dentistry; Dr. McCauley is Chair and William K. and Mary Anne Najjar Professor of Dentistry; Dr. Green is Director, Curriculum and Instructional Services; and Dr. Inglehart is Associate Professor, Department of Periodontics and Oral Medicine - all at the School of Dentistry, University of Michigan. Direct correspondence and requests for reprints to Dr. Marita R. Inglehart, Department of Periodontics and Oral Medicine, School of Dentistry, University of Michigan, 1011 North University Avenue, Ann Arbor, MI 48109-1078; 734-763-8073 phone; 734-763-5503 fax; mri@umich.edu.

Keywords: dental faculty, dental hygiene faculty, faculty retention, mentoring, social support

Submitted for publication 6/28/10; accepted 9/23/10

$\mathrm{I}$ $\mathrm{n}$ recent years, institutions of higher education in the United States have been faced with significant challenges, including rising costs and shrinking budgets. In dental schools, a shortage of dental faculty members presents a clear threat to the future of dental education. Recent reports have shown that more than 400 budgeted faculty positions in U.S. dental schools remain vacant. ${ }^{1-3}$ Issues such as increased student loan debts, meeting tenure requirements, and coping with demanding schedules affect faculty recruitment and retention. ${ }^{4-8}$ It is therefore crucial to retain competent faculty members in dental schools. One central question is how to support especially newly appointed younger faculty members in their efforts to gain tenure and promotion and to be successful in their teaching, research, and service activities. Mentoring can be a valuable tool in this endeavor. $^{9-12}$
In a professional setting such as the dental school environment, the term "mentor" implies that more experienced faculty members or students provide insight and support to less experienced peers or students with the goal of ensuring their success. Research on the role of mentoring in academic medicine ${ }^{13,14}$ and in nursing ${ }^{15-17}$ has a long tradition. This research has documented the positive effects of mentoring in these contexts, such as allowing the mentees to become socialized to their faculty responsibilities ${ }^{17-19}$ and assisting them in their career advancement, personal growth, and development as well as reducing personal stress..$^{20,21}$ In dentistry, research on mentoring is relatively scarce. ${ }^{22-24}$ This case study of a mentoring program that took place in a large department of a Midwestern dental school over a six-year time span therefore offers the rare opportunity 1) to evaluate whether faculty members' 
perceptions of support from colleagues as well as their expectations concerning what mentoring should focus on changed over this period and 2) to determine how junior versus senior faculty members and mentors versus mentees differed in their perceptions of faculty roles, their self-perceived competence, and their awareness of departmental expectations at the end of the program.

\section{Methods}

This study was reviewed by the Institutional Review Board for the Health Sciences at the University of Michigan and was granted exempt status.

In 2002, twenty-five of the thirty-six faculty members ( 57 percent not tenured; 43 percent tenured) in the periodontics department of the University of Michigan School of Dentistry responded to a baseline survey (response rate: 69 percent). In 2008, thirtyseven of the fifty-four faculty members returned a follow-up survey (response rate: 69 percent). Of these thirty-seven respondents, thirty-two indicated that they were employed full-time and five part-time; nineteen reported being junior and eighteen being senior faculty members; and twenty-three ( 62 percent) said they were not tenured and fourteen (38 percent) were tenured.

When this departmental program was developed, a review of the literature found that there were no clear guidelines for how to develop effective mentoring programs $\mathrm{s}^{25}$ nor were there clear criteria for how to evaluate the success of mentoring relationships $^{26}$ at that time. The departmental efforts were therefore mainly guided by the mission of the department to improve the quality of the faculty experience, to help ensure success in the academic environment for all faculty members, and to retain qualified faculty members in the department. In order to support these objectives, the department chair established a mentoring committee in 2002 and charged this committee with developing a mentoring program. The committee decided to administer a baseline survey that explored faculty members' perceptions of support by colleagues, their thoughts concerning the role of mentors, and their awareness of departmental expectations. This initial survey was based on surveys used in two previous studies of faculty mentoring issues by Fox et al. ${ }^{14}$ and Sands et al. ${ }^{27}$

Faculty members were recruited with an email by the department chair that encouraged them to respond anonymously to the survey on a secure website. Based on these results, a mentoring program was developed and implemented. In 2008, a followup survey was administered to document change over time. In addition to the questions included in the first survey, background information about the respondents' experiences with mentoring was collected as well. Again, a recruitment e-mail by the department chair was sent to all faculty members, and the respondents answered the questions anonymously on a secure website. lowing:

The key features of the program were the fol-

1. To make appropriate mentoring available consistent with each person's needs and aspirations.

2. To offer mentoring for faculty members at every level of their careers, while acknowledging that mentoring takes different forms as a faculty member advances through the professional ranks.

3. To offer mentoring to all new faculty members in the following manner:

- When a new faculty member joined the department or when an existing faculty member expressed interest in meeting with a mentor, that individual responded to a short informal survey asking about his or her needs. This information was used by the mentoring committee or chair as a basis for a discussion with the faculty member.

- Based on this discussion, the committee selected a prospective mentor and determined if this mentor would be willing to serve for an initial one-year term that could be continued if wanted by both mentor and mentee. The mentee then contacted the mentor within one week, and the mentor-mentee team met as soon as possible at a mutually convenient time and place for a first time. The committee offered suggestions to the mentors concerning potential discussion areas of interest such as providing information about the activities and life in the dental school, the workings of the department, and expectations for teaching, service, and scholarly activities. However, it was up to the mentor-mentee pair to decide how often they wanted to meet and which topics they discussed.

- After six and twelve months, the committee chair met with the mentee and mentor separately to ensure that the relationship was working to the satisfaction of both partners. 
- After the first year, the mentee was asked to report on the success of the program and to identify additional mentors as needed. At this time, the existing relationship could continue, or an exchange of mentors could occur.

\section{Results}

The first three questions of the baseline survey were concerned with the respondents' thoughts concerning mentoring programs. On average, the respondents agreed with the statement "I see a need for a mentoring program" (on a scale from $1=$ disagree strongly to $5=$ agree strongly: mean $=3.96$ ). They also agreed on average with the statements "As a mentee, I would prefer to choose my mentor(s)" (3.84) and "I would prefer to have scheduled meetings with my mentor" (3.79). These responses were used when developing the mentoring program.

Before analyzing whether the respondents in 2002 differed in their answers from the respondents surveyed in 2008, it is important to consider whether these two groups varied in a systematic way. While no information was collected in 2002 about whether the respondents were employed full-time or parttime or whether they were junior or senior faculty, the subjects did indicate whether they were tenured or not tenured. A comparison of the percentages of faculty members who were tenured versus not tenured in 2002 and 2008 showed that these percentages did not differ significantly (2002: 57 percent untenured, 43 percent tenured; 2008: 62 percent untenured, 38 percent tenured; chi square $=.188$; d.f. $=1 ; p=.665$ ).

Concerning changes in respondents' perceptions of support from colleagues, the data showed that the responses in 2008 were significantly more positive than in 2002 when the respondents evaluated how much they agreed that they have colleagues who were available to help with the respondents' successful development concerning their research (2002: 3.26 vs. 2008: $4.09 ; \mathrm{p}=.005$ ), their teaching (3.46 vs. 4.03; $\mathrm{p}=.036)$, and their clinical research activities ( 3.22 vs. $4.00 ; p=.009$ ) (see Table 1 ). The second significant difference between the responses in 2002 and 2008 was found when analyzing the respondents' expectations concerning the role of mentors. As can be seen in Table 1, the data showed that the faculty members' expectations in 2008 were higher than in 2002. For example, in 2008 the respondents more strongly agreed that mentors should be a role model (2002: 4.17 vs. 2008 : 4.69 ; $p=.001$ ); provide con- structive criticism/feedback (4.33 vs. $4.68 ; \mathrm{p}=.013$ ), encouragement and coaching ( 4.00 vs. $4.41 ; \mathrm{p}=.023$ ), and information about university policies and procedures (3.92 vs. 4.36; $\mathrm{p}=.023$ ); and help promote their involvement in professional networks (3.83 vs. $4.33 ; \mathrm{p}=.006)$ and professional visibility (3.78 vs. $4.28 ; \mathrm{p}=.012$ ).

In addition to analyzing these differences in the closed ended responses in 2002 versus 2008, the open-ended responses in 2008 concerning the mentoring program were interesting as well. The mentees agreed that the program had been helpful to them in statements such as "The program has been a big help"; "My mentors got me started and were available"; "My mentor is excellent: professional and very helpful"; and "Having formal department support for mentoring is wonderful." Mentors also had a positive response to the program, providing statements such as "I have felt satisfaction with sharing knowledge, experience, and support with others"; "It has been great to see professional and personal growth in the person I have mentored"; "I look forward to our regular meetings to discuss a variety of issues, both professional and personal"; "I feel that I have gotten as much out of the relationship as the one mentored"; and "Gratification in seeing my mentees do well (advancement/promotion and success in obtaining positions, funding, and publications)." Statements concerning the value of the program in general were also quite encouraging. Examples of such statements were "The mentoring program is something to be proud of"; "A formalized program is important. It informs new faculty that we recognize the critical nature of mentoring and that it is taken seriously for professional development"; and "The positive attitude toward mentoring in this department is great!"

Problems addressed in the open-ended responses were concerned with the fact that the time commitment for mentoring can be an issue at times and that effective mentoring can be challenging. Suggestions for changes focused on organizational matters such as offering events that bring mentors/ mentees together or continuing to encourage the use of mentoring.

In addition to analyzing the differences in the perceptions of support by colleagues and in mentoring expectations between 2002 and 2008, it is also important to determine how junior versus senior faculty members and mentors versus mentees differed in their perceptions of faculty roles, their self-perceived competence, and their awareness of departmental expectations at the end of the program. 
Table 1. Perceptions of support from colleagues and expectations concerning the role of mentors in 2002 versus 2008

\begin{tabular}{|c|c|c|c|}
\hline & $\begin{array}{c}2002 \\
\text { Mean (SD) }\end{array}$ & $\begin{array}{c}2008 \\
\text { Mean }(\mathrm{SD})\end{array}$ & $\mathrm{p}$ \\
\hline \multicolumn{4}{|l|}{$\begin{array}{l}\text { My colleagues are interested in and available to help with my successful } \\
\text { professional development in the following areas: }\end{array}$} \\
\hline - research & $3.26(1.18)$ & $4.09(.72)$ & .005 \\
\hline - teaching & $3.46(1.14)$ & $4.03(.71)$ & .036 \\
\hline - clinical research & $3.22(1.20)$ & $4.00(.71)$ & .009 \\
\hline - administration & $3.17(1.05)$ & $3.56(.95)$ & .146 \\
\hline \multicolumn{4}{|l|}{ I would expect my mentor(s) to provide } \\
\hline - role model & $4.17(.65)$ & $4.69(.47)$ & .001 \\
\hline - constructive criticism/feedback & $4.33(.57)$ & $4.68(.48)$ & .013 \\
\hline - information about formal expectations for promotion and tenure & $4.29(.91)$ & $4.53(.61)$ & .232 \\
\hline - encouragement and coaching & $\mathbf{4 . 0 0}(.85)$ & $\mathbf{4 . 4 1}(.50)$ & .023 \\
\hline - advice about research opportunities & $4.22(.52)$ & $4.39(.55)$ & .237 \\
\hline - advice about publication outlets & $3.87(1.01)$ & $4.37(.60)$ & .021 \\
\hline - information about university policies and procedures & $3.92(.83)$ & $4.36(.64)$ & .023 \\
\hline - involvement in professional networks & $3.83(.78)$ & $4.33(.59)$ & .006 \\
\hline - help in promoting my professional visibility & $3.78(.80)$ & $4.28(.66)$ & .012 \\
\hline - introductions to people who can further my career & $3.91(.60)$ & $4.24(.76)$ & .082 \\
\hline - advice about committee work & $3.95(.58)$ & $4.19(.57)$ & .133 \\
\hline - help with teaching & $4.09(.52)$ & $4.08(.60)$ & .969 \\
\hline - reviews of drafts of papers & $3.61(1.08)$ & $4.06(.77)$ & .092 \\
\hline - help making difficult career decisions & $3.78(.60)$ & $4.03(.76)$ & .197 \\
\hline - emotional support & $3.50(.93)$ & $3.97(.90)$ & .052 \\
\hline - advice about people & $3.58(1.02)$ & $3.89(.81)$ & .194 \\
\hline - nomination for honors & $3.62(.59)$ & $3.89(.61)$ & .105 \\
\hline - help in promoting an equal relationship & $3.57(.79)$ & $3.86(.65)$ & .129 \\
\hline - collaboration on research/publications/teaching & $3.75(1.15)$ & $3.81(1.00)$ & .827 \\
\hline - advice about social norms & $3.30(1.15)$ & $3.78(.90)$ & .082 \\
\hline - defense for criticism & $3.00(1.04)$ & $3.33(.83)$ & .179 \\
\hline - social activities (recreation, cultural events, eating out) & $2.65(.98)$ & $2.86(.89)$ & .390 \\
\hline - help with personal problems & $2.74(1.10)$ & $2.78(1.02)$ & .891 \\
\hline
\end{tabular}

Note: Responses ranged from $1=$ strongly disagree to $5=$ strongly agree. The bolded numbers highlight the significant differences between the average responses in 2002 and 2008.

Source for first question: Fox EC, Waldron JA, Bohnert P, Hishinuma ES, Nordquis CR. Mentoring new faculty in a department of psychiatry. Acad Psychiatry 1998;22(3):98-106.

Source for second question: Sands RG, Parson A, Duane J. Faculty mentoring in a public university. J Higher Educ 1991;62(2):174-93.

Table 2 shows that, overall, both junior and senior faculty members were very positive about being a member of the faculty. Both groups on average agreed strongly with the statement "I am excited about being a member of the faculty." However, junior faculty members were significantly less likely than senior faculty members to agree that they had a reasonable grasp of the roles and responsibilities of being a faculty member (junior: 4.05 vs. senior 4.65; $\mathrm{p}<.05$ ), of the general philosophy of the department ( 3.84 vs. $4.67 ; p<.01$ ), and of the general workings of the department (3.68 vs. $4.44 ; \mathrm{p}<.01$ ). In addition, junior faculty members indicated that they were on average less aware than senior faculty members of research opportunities in the department (3.44 vs. $4.35 ; \mathrm{p}<.01)$, teaching issues in the department (3.39 vs. $4.11 ; \mathrm{p}<.05)$, research issues in the department (3.11 vs. $3.89 ; \mathrm{p}<.05)$, and administrative issues in the department ( 3.00 vs. $3.89 ; \mathrm{p}<.01)$.

While junior faculty members did not differ from senior faculty members in their self-perceived competence concerning teaching, they were less likely to evaluate themselves as competent in research-related matters and in administrative competence $(2.75$ vs. $4.28 ; p<.001)$. For example, junior faculty members assessed their competence concerning writing a paper for a journal submission (4.12 vs. $4.67 ; \mathrm{p}<.05)$, presenting at non-departmental 
conferences ( 3.88 vs. $4.56 ; \mathrm{p}<.05)$, and conducting research (3.56 vs. $4.39 ; \mathrm{p}<.01)$ as lower compared to senior faculty members. In addition, junior faculty members reported that they were on average less aware of departmental expectations concerning attending faculty meetings (3.26 vs. $4.33 ; \mathrm{p}<.01)$, membership on faculty committees (3.06 vs. 4.53 ; $\mathrm{p}<.001)$, participating in resident case conferences and seminars ( 2.87 vs. $4.08 ; \mathrm{p}<.01)$, and research productivity (3.56 vs. $4.65 ; \mathrm{p}<.01)$.

Most of these differences were mirrored in differences in the faculty member role expectations, perceived competence evaluations, and departmental expectations of mentees and mentors.

\section{Discussion}

In 1990, Zelditch defined mentors in a comprehensive manner as "advisors with career experience willing to share their knowledge; supporters who give emotional and moral encouragement; tutors who give specific feedback on one's performance; masters, in the sense of employers to whom one is apprenticed; sponsors, sources of information about, and aid in obtaining opportunities; models of identity, of the kind of person one should be to be an academic." 28 This comprehensive definition captures the essence of what faculty mentors could and should be for their mentees. The results of our six-year mentoring program showed that such a program could actually result in significantly more positive perceptions of collegial support in the department. Given that positive social support can play a constructive role when coping with stress, ${ }^{29}$ this outcome is significant. In addition, it was interesting to see that, at the end of the six-year period, some of the faculty members' expectations concerning mentors had changed to expecting more from mentors compared to 2002. For example, in 2008, the respondents indicated more strongly that a mentor should be a role model, give constructive criticism and feedback, and promote professional visibility than in 2002. One might interpret this rise of positive expectations as a result of having either participated in the mentoring program and experienced the value of this program or having observed the positive effects of mentoring in others.

When considering the outcomes of the mentoring program, one could analyze whether junior and senior faculty members' self-perceived competence and awareness of departmental expectations and their faculty role were relatively similar at the end of the six-year program. The results showed that selfperceived competence and departmental expectations concerning teaching as well as confidence in their clinical competence were actually not significantly different between junior and senior faculty members. However, there still was a considerable gap in selfperceived confidence and expectations concerning research and administrative activities. One could interpret these findings as an indication that junior faculty members might be lacking some implicit knowledge about academic citizenship. This finding should challenge future mentoring activities to provide the experiences necessary for younger faculty members to develop the skills necessary to live up to expectations concerning research productivity and administrative tasks. Specialized mentoring programs concentrating on research in other fields showed that these programs can be quite successful when they focus centrally on research. ${ }^{26}$ In addition, mentoring programs for subgroups of faculty members such as female faculty members or underrepresented minority faculty members have also been shown to be quite successful. ${ }^{30}$ The fact that mentors seem to have a clearer insight into the departmental and faculty role expectations and see themselves as more competent than the mentees supports the assumption that the mentors have the qualifications to engage their mentees in activities that might benefit the mentees in these areas.

The major limitation of this study is primarily that it was a case study of a mentoring program limited to one department in a dental school. Such a case study can clearly only explore the issues of how to mentor dental faculty members successfully. An additional limitation of this study was that no background information about the respondents' gender, age, or ethnicity/race was collected in order to allow an anonymous response to the surveys. Future research could explore whether these personal characteristics would have moderated the outcomes of a mentoring program.

\section{Recommendations}

Despite these limitations, the results showed the increase in perceived collegial support and positive expectations of mentoring that suggests that such a program might be helpful to other departments as well. More specifically, several lessons learned can be shared with other departments. Based on our experi- 
Table 2. Responses of junior versus senior faculty members and of mentors versus mentees in 2008

Junior Faculty Senior Faculty

Mentee

Mentor

Faculty member role ${ }^{+}$

I am excited about being a member of the faculty.

I see myself as a faculty member five years from now.

I receive departmental information on a timely basis.

It is important for me to be able to discuss personal issues with a departmental colleague(s) if I choose.

4.47

(.70)

4.00

$(1.14)$

4.05

4.16

$(83$

I have a reasonable grasp/idea

- of the roles and responsibilities in being a faculty member.

- of the general philosophy of our department.

- as to the general workings of our department

I am aware of

- research opportunities available within our department.

- clinical issues.

- the teaching issues that face our department.

- the research issues within our department.

- the administrative issues within our department.

Self-perceived competence: I feel prepared to ${ }^{\dagger}$

- teach dental/hygiene students.

- supervise dental/hygiene students

- be a competent clinician.

- write a paper for journal submission

$\begin{array}{cccc}\mathbf{4 . 0 5} & \mathbf{4 . 6 5 *} & 4.23 & 4.45 \\ (.85) & (.49) & (.60) & (.69) \\ \mathbf{3 . 8 4} & \mathbf{4 . 6 7 ^ { * * }} & \mathbf{4 . 0 0} & \mathbf{4 . 6 7 *} \\ (.77) & (.59) & (.58) & (.65) \\ \mathbf{3 . 6 8} & \mathbf{4 . 4 4 ^ { * * }} & 3.69 & 4.42 \neq \\ (.82) & (.86) & (.75) & (1.00) \\ & & & \\ \mathbf{3 . 4 4} & \mathbf{4 . 3 5 * *} & 3.50 & 4.27 \neq \\ (1.04) & (.79) & (1.00) & (.91) \\ 3.72 & 4.00 & 3.62 & 4.08 \\ (.75) & (.79) & (.77) & (.67) \\ \mathbf{3 . 3 9} & \mathbf{4 . 1 1 *} & 3.31 & \mathbf{4 . 1 7 *} \\ (1.04) & (.68) & (.95) & (.58) \\ \mathbf{3 . 1 1} & \mathbf{3 . 8 9 *} & 3.08 & 3.78 \\ (.94) & (1.02) & (.76) & (1.14) \\ \mathbf{3 . 0 0} & \mathbf{3 . 8 9 * *} & \mathbf{2 . 9 2} & \mathbf{3 . 9 1 *} \\ (1.00) & (.83) & (.79) & (1.00) \\ & & & \\ & & & 4.82 \\ 4.61 & 4.82 & 4.62 & (.41) \\ (.61) & (.39) & (.65) & 4.60 \\ 4.50 & 4.73 & 4.55 & (.52) \\ (.52) & (.46) & (.52) & 4.50 \\ 4.67 & 4.53 & 4.69 & (.71) \\ (.49) & (.64) & (.48) & 4.58 \\ \mathbf{4 . 1 2} & \mathbf{4 . 6 7 *} & 4.17 & \\ (.86) & (.59) & (.94) & \end{array}$

4.67

(.49)

4.33

(1.16)

$4.55 \neq$

(.52)

3.92

$(1.00)$

(.69)

$.65)$

$.42 \ddagger$

.00)

$27 \pm$

.67)

.58)

78

.14) 
- present at non-departmental conferences.

$\begin{array}{lccc}4.13 & 4.47 & 4.40 & 4.44 \\ (.92) & (.74) & (.70) & (.73) \\ \mathbf{3 . 8 8} & \mathbf{4 . 5 6 *} & 4.08 & 4.33 \\ (1.11) & (.51) & (.65) & (.90) \\ 4.11 & 4.31 & 4.15 & 4.45 \\ (.83) & (1.08) & (.80) & (.69) \\ 4.00 & 4.43 & 4.30 & 4.44 \\ (.93) & (.76) & (.68) & (.73) \\ \mathbf{3 . 5 6} & \mathbf{4 . 3 9 * *} & 3.92 & 4.17 \\ (.92) & (.78) & (.90) & (.72) \\ 3.71 & 3.71 & 3.60 & 3.44 \\ (.73) & (1.20) & (.70) & (1.33) \\ \mathbf{2 . 7 5} & \mathbf{4 . 2 8 * * *} & \mathbf{2 . 9 2} & \mathbf{4 . 4 5 * * *} \\ (.86) & (.75) & (.90) & (.52)\end{array}$

I am aware of departmental expectations ${ }^{\dagger}$

- for attendance at faculty-related meetings.

$\begin{array}{cccc}\mathbf{3 . 2 6} & \mathbf{4 . 3 3} * * & 3.46 & 4.25 \neq \\ (1.10) & (.84) & (1.05) & (.97) \\ 2.63 & 3.00 & 2.64 & 3.14 \\ (1.03) & (.90) & (1.12) & (1.07) \\ 2.82 & 2.91 & 2.92 & 3.38 \\ (1.02) & (1.14) & (1.00) & (1.19) \\ 3.78 & 4.44 & 3.38 & 4.40 \neq \\ (1.31) & (.90) & (1.33) & (1.08) \\ \mathbf{3 . 0 6} & \mathbf{4 . 5 3 * * *} & \mathbf{3 . 0 0} & \mathbf{4 . 3 6} * \\ (1.06) & (.62) & (1.21) & (.81) \\ \mathbf{2 . 8 7} & \mathbf{4 . 0 8}^{* *} & 3.10 & 4.00 \\ (1.06) & (.95) & (1.20) & (1.07) \\ \mathbf{3 . 5 6} & \mathbf{4 . 6 5 * *} & \mathbf{3 . 5 5} & \mathbf{4 . 5 5 * *} \\ (.96) & (.61) & (.93) & (.69) \\ 3.15 & 3.91 & 3.20 & 4.20 \\ (1.35) & (1.38) & (1.48) & (1.30) \\ \mathbf{3 . 6 9} & \mathbf{4 . 4 6}^{*} & 3.89 & 4.25 \\ (.86) & (.52) & (.78) & (.71)\end{array}$

- for private practice/dental faculty associate practice.

\#Responses ranged from $1=$ strongly disagree to $5=$ strongly agree.

The bolded numbers highlight the significant differences between the average responses of junior vs. senior faculty members and of mentees vs. mentors. ${ }^{*} \mathrm{p} \leq .05 ;{ }^{* *} \mathrm{p} \leq .01 ; * * * \mathrm{p} \leq .001$ 
ences with this program, we offer recommendations in the following areas.

Who should be mentored? This faculty mentoring program was developed to enhance the experience of incoming and existing faculty members. It seemed beneficial that even faculty members with advanced status in the department should receive mentoring concerning the next steps in their careers.

How should mentoring be initiated and implemented? The departmental mentoring committee should assess needs and wants of mentees and then match mentees with mentors for an initial brief and informal mentor/mentee meeting. Both sides would be under no obligation to engage in a long-term relationship; however, the mentor and mentee could continue to meet if both wish to do so. While traditional mentoring relationships might involve mentees' voluntarily seeking out a mentor in their own department, other options have also proven effective. For example, mentoring relationships that were initiated by the department chair or even a dean have also resulted in constructive interactions. In addition, mentoring pairs formed across departments and schools have worked as well as pairs from within departments. In the case in which a faculty member from another department serves as a mentor for a junior faculty member, the mentoring committee should advise the establishment of a co-mentorship pair, in which one member of the mentoring pair can be from within the department.

What responsibilities do mentors have? The mentor's primary responsibilities should be to provide guidance to the mentee in professional and personal (if requested) issues, to participate in open and honest goal setting and feedback for academic career advancement, and to introduce the mentee to individuals who can facilitate career advancement.

What responsibilities do mentees have? Potential mentees should clearly articulate their career development needs, since meeting these needs will form the structure of the mentoring relationship. They should actively engage their mentors to seek out career, professional, and personal advice on issues of teaching, research, promotion, tenure, and the collegial culture and should be available for networking opportunities and introductions to key individuals by their mentors. Junior faculty mentees should select a senior faculty mentor who will guide them in preparing for promotion, thus supporting the guidance and counseling of the department chair.

What responsibilities does the department chair have? The chair has the ultimate respon- sibility for ensuring the mentoring of all faculty members in his or her department and facilitating opportunities for faculty career advancement. The chair must maintain an active role in mentoring all faculty members, yet in a large department this may involve a greater dependence on a formal mentoring program. In such cases, senior faculty members who act as mentors should be acknowledged for their contributions. The mentoring committee serves in an advisory role to improve all mentoring activities in the department. The chair must clearly articulate departmental policies for teaching, scholarly activities, service, patient care and faculty practice, promotion/advancement/tenure, moral/ethical concerns, and financial rewards to ensure that mentors and mentees can develop appropriate expectations. In addition, the chair can also consider providing opportunities for mentor-mentee meetings as part of regularly scheduled events such as departmental meetings or retreats.

In summary, a structured departmental mentoring program can clearly facilitate activities that are beneficial in advising or guiding mentees through their academic careers. It has to be clear that not all needs of a faculty member, whether a junior or senior faculty member, can be met by a single individual, nor can mentoring relationships be legislated by such a committee. One responsibility of a committee and mentors is therefore to assist in identifying multiple mentoring relationships inside and outside of the department, whether in other departments of the dental school or in other units in the university. The primary objective of the mentorship program described in this case study was to attract, develop, and retain faculty members capable of demonstrating excellence in teaching, research, and service-a goal that will support efforts to reduce the faculty shortage in dentistry.

\section{Acknowledgments}

We want to dedicate this article to Prof. Chris Klausner (1949-2010) whose dedication to our students, patients, and colleagues made a big difference for all of us. She was the best role model of what a mentor could be, and her contributions will not be forgotten. We want to thank Dr. Dennis Lopatin for his support for the first survey, Dr. Will Giannobile for his thoughtful contributions to this study, and Brittany Williams for helping with the preparation of the data for analysis and preparation of the tables. 


\section{REFERENCES}

1. Chmar JE, Weaver RG, Valachovic RW. Dental school vacant budgeted faculty positions: academic year 2004-05. J Dent Educ 2006;70(2):188-98.

2. Chmar JE, Weaver RG, Valachovic RW. Dental school vacant budgeted faculty positions, academic years 2005-06 and 2006-07. J Dent Educ 2008;72(3):370-85.

3. Livingston HM, Dellinger TM, Hyde JC, Holder R. The aging and diminishing dental faculty. J Dent Educ 2004; 68(3):345-54.

4. Walker MP, Duley SI, Beach MM, Deem L, Pileggi R, Samet N, et al. Dental education economics: challenges and innovative strategies. J Dent Educ 2008;72(12):1440-9.

5. Goodacre C, Loveless W. Dental faculty recruitment at Loma Linda University School of Dentistry. J Calif Dent Assoc 2005;33(10):787-92.

6. Wood J, Rutkauskas JS, Seewoester S. American Academy of Pediatric Dentistry survey of U.S. pediatric dentistry faculty members. Pediatr Dent 2006;28(6):537-42.

7. Chmar JE, Harlow AH, Weaver RG, Valachovic RW. Annual ADEA survey of dental school seniors, 2006 graduating class. J Dent Educ 2007;71(9):1228-53.

8. Weaver RG, Chmar JE, Haden NK, Valachovic RW. Annual ADEA survey of dental school seniors: 2004 graduating class. J Dent Educ 2005;69(5):595-619.

9. Friedman PK, Arena C, Atchison K, Beemsterboer PL, Farsai P, Giusti JB, et al. Report of the ADEA president's commission on mentoring. J Dent Educ 2004;68(3):390-6.

10. Schrubbe KF. Mentorship: a critical component for professional growth and academic success. J Dent Educ 2004; 68(3):324-8.

11. Rogér JM, Wehmeyer MMH, Milliner MS. Reflections on academic careers by current dental school faculty. J Dent Educ 2008;72(4):448-57.

12. Peterson MR. Academic tenure and higher education in the United States: implications for the dental education workforce in the twenty-first century. J Dent Educ 2007;71(3): 354-64.

13. Berk RA, Berg J, Mortimer R, Walton-Moss B, Yeo TP. Measuring the effectiveness of faculty mentoring relationships. Acad Med 2005;80(1):66-71.

14. Fox EC, Waldron JA, Bohnert P, Hishinuma ES, Nordquis CR. Mentoring new faculty in a department of psychiatry. Acad Psychiatry 1998;22(3):98-106.

15. Dunham-Taylor J, Lynn CW, Moore P, McDaniel S, Walker JK. What goes around comes around: improving faculty retention through more effective mentoring. J Prof Nurs 2008;24(6):337-46.
16. Fields WL. Mentoring in nursing: a historical approach. Nurs Outlook 1991:257-61.

17. Fuszard B, Taylor LJ. Mentorship. In: Bradshaw M, Lowenstein A, eds. Innovative teaching strategies in nursing and health professions. $4^{\text {th }}$ ed. Sudbury, MA: Jones and Bartlett, 2007:200-8.

18. Rogers JC, Holloway RL, Miller SM. Academic mentoring and family medicine's research productivity. Fam Med 1990; 22:186-90.

19. Stange KC, Hekelman FP. Mentoring needs and family medicine faculty. Fam Med 1990;22:183-5.

20. Bland CJ, Schmitz CC, Stritter FT, Henry RC, Aluise JJ. Successful faculty in academic medicine. New York: Springer, 1990.

21. Kirsling RA, Kochar MS. Mentors in graduate medical education at the Medical College of Wisconsin. Acad Med 1990;65:272-4.

22. Bibb CA, Lefever KH. Mentoring future dental educators through an apprentice teaching experience. J Dent Educ 2002;66(6):703-9.

23. Corbet E, Akinwade J, Duggal R, Gebreegziabher G, Hirvikangas $\mathrm{H}$, et al. Staff recruitment, development, and global mobility. Eur J Dent Educ 2008;12(Suppl 1): 149-60.

24. Nesbitt PE, Inglehart MR, Sinkford JC. Work environment perceptions of full-time dental educators: does gender matter? J Dent Educ 2003;67(8):916-24.

25. Morin KH, Ashton KC. Research on faculty orientation programs: guidelines and directions for nurse educators. J Prof Nurs 2004;20:239-50.

26. Brown RT, Daly BP, Leong FTL. Mentoring in research: a developmental approach. Prof Psychol: Res Practice 2009; 40(3):306-13.

27. Sands RG, Parson A, Duane J. Faculty mentoring in a public university. J Higher Educ 1991;62(2):174-93.

28. Zelditch M. Mentor roles. Proceedings of the 32nd Annual Meeting of the Western Association of Graduate Schools, Tempe, AZ, March 16-18, 1990:11.

29. Inglehart MR. Reactions to critical life events: a socialpsychological analysis. New York: Praeger, 1991.

30. Kosoko-Lasaki O, Sonnino RE, Voytko ML. Mentoring for women and underrepresented minority faculty and students: experience at two institutions of higher education. J Natl Med Assoc 2006;98(9):1449-59. 